\title{
Detection Of $\mathrm{Au}^{+}$Ions During Fluorine Gas-Assisted TOF-SIMS For Complete Elemental Characterization Of Microbatteries
}

\author{
Agnieszka Priebe ${ }^{1, *}$, Jordi Sastre ${ }^{2}$, Moritz H. Futscher ${ }^{2}$, Jakub Jurczyk1,3, Marcos V.
} Puydinger dos Santos ${ }^{1, \dagger}$, Yaroslav E. Romanyuk ${ }^{2}$ and Johann Michler ${ }^{1}$

'Empa, Swiss Federal Laboratories for Materials Science and Technology, Laboratory for Mechanics of Materials and Nanostructures, Feuerwerkerstrasse 39, CH-36o2 Thun, Switzerland

${ }^{2}$ Empa, Swiss Federal Laboratories for Materials Science and Technology, Laboratory for Thin Films and Photovoltaics, Überlandstrasse 129, Dübendorf, $\mathrm{CH}-8600$ Switzerland

3AGH University of Science and Technology Krakow, Faculty of Physics and Applied Computer Science, Al. Mickiewicza 30, 30-059 Kraków, Poland

*Corresponding author: agnieszka.priebe@empa.ch 


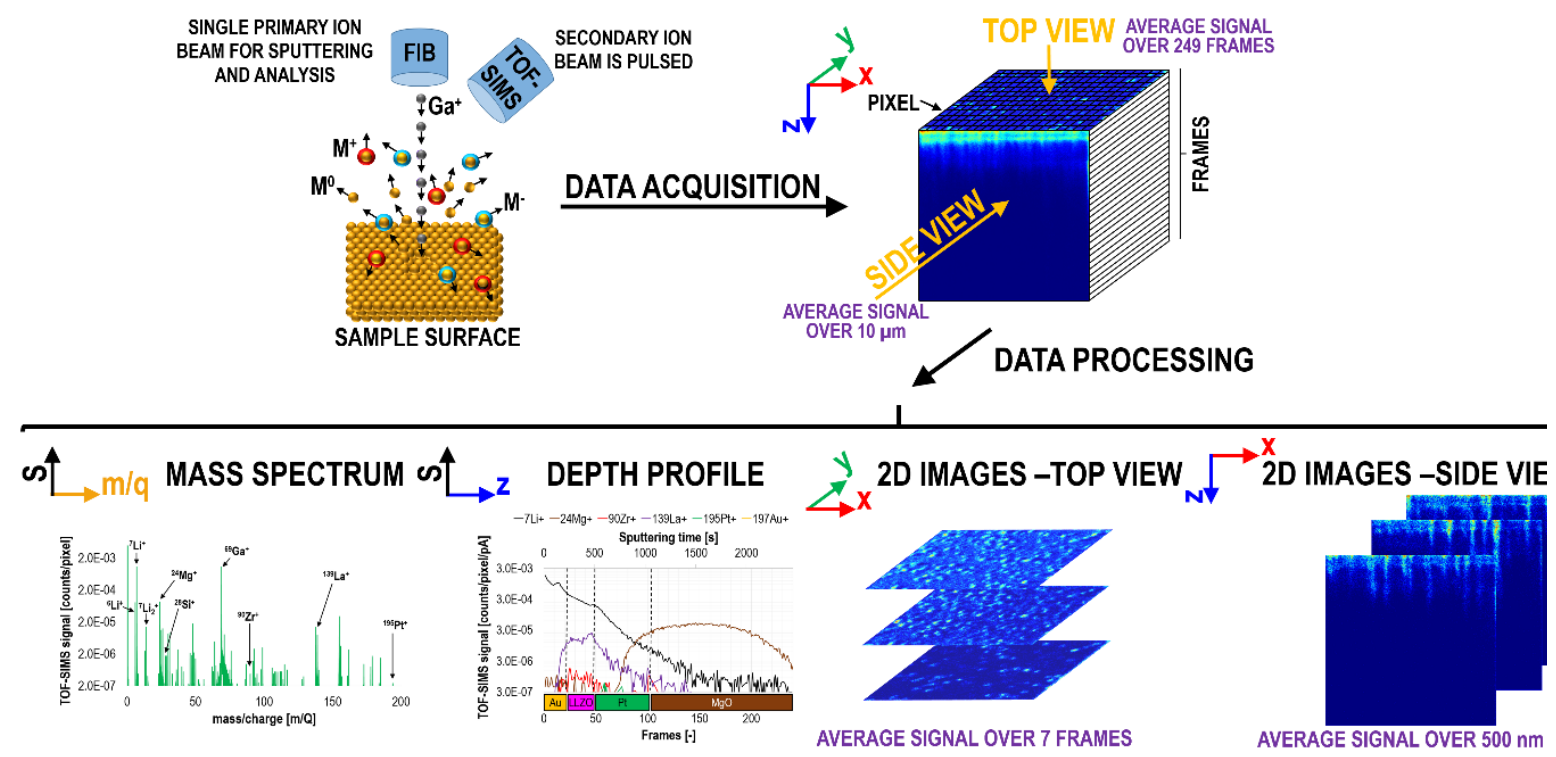

Figure S1. Data acquisition and representation in the case of HV-compatible TOF-SIMS detectors (such as HTOF and CTOF) integrated within a FIB/SEM instrument. In this case, a continuous $\mathrm{Ga}^{+}$beam is used for both sputtering and analysis (dynamic-SIMS). As a result of surface bombardment, a certain population of secondary species (neutral atoms and molecules as well as positively- and negatively- charged ions) is generated. The ions are guided towards a mass analyser and the secondary ion beam is pulsed. During the data acquisition, only positive or negative ions can be detected during a single measurement (under standard vacuum conditions). The primary ion beam scans the sample surface pixel by pixel and frame (scan) by frame allowing a 4D data set (i.e. $x, y, z$ coordinates and an associated mass spectrum for each data point) to be obtained. Consequently, the chemical data can be represented in the form of mass spectra, depth profiles and 2D chemical maps (in the lateral plane and in depth). 3D data reconstruction is also possible with dedicated software.

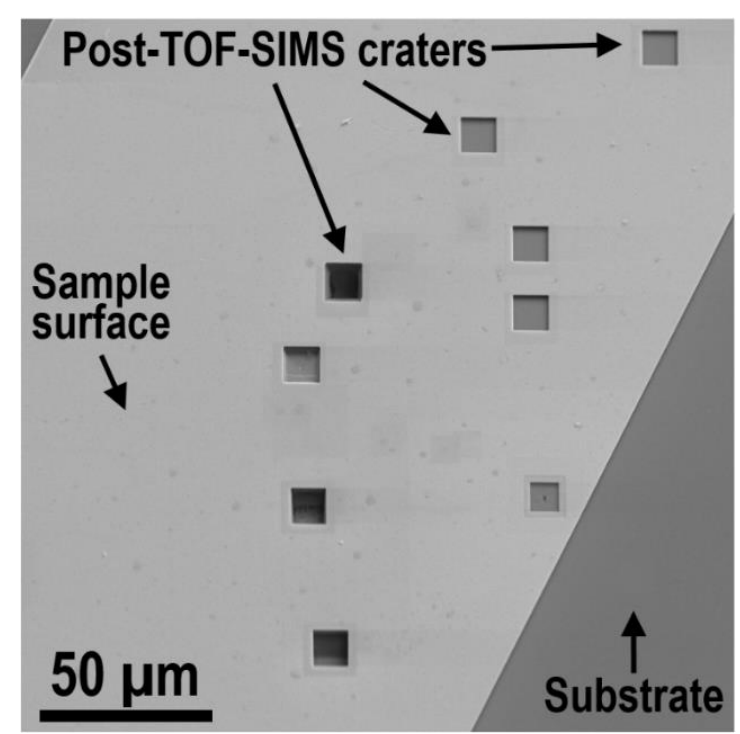

Figure S2. The SEM image of the Au sample showing post-TOF-SIMS craters. 
Table S1. Deposition parameters of $\mathrm{Au} / \mathrm{Cr} / \mathrm{SiO}_{2} / \mathrm{Si}$ sample.

\begin{tabular}{|c|c|c|c|c|c|c|c|}
\hline Layer & Source & $\begin{array}{l}\text { Power } \\
{[W]}\end{array}$ & $\mathrm{T}\left[{ }^{\circ} \mathrm{C}\right]$ & $\begin{array}{l}\text { Average deposi- } \\
\text { tion rate }[\AA ̊ / s]\end{array}$ & $\begin{array}{l}\text { Base pressure } \\
{[\mathrm{mbar}]}\end{array}$ & $\begin{array}{l}\text { Process pres- } \\
\text { sure }[\mathrm{mbar}]\end{array}$ & $\begin{array}{l}\text { Argon flow } \\
{[\mathrm{sccm}]}\end{array}$ \\
\hline $\mathrm{Cr}$ & \multirow{2}{*}{$\mathrm{DC}$} & 350 & \multirow{2}{*}{20} & 5.8 & \multirow{2}{*}{$1 \times 10^{-6}$} & \multirow{2}{*}{$5 \times 10^{-3}$} & \multirow{2}{*}{30} \\
\hline $\mathrm{Au}$ & & 250 & & 12.3 & & & \\
\hline
\end{tabular}
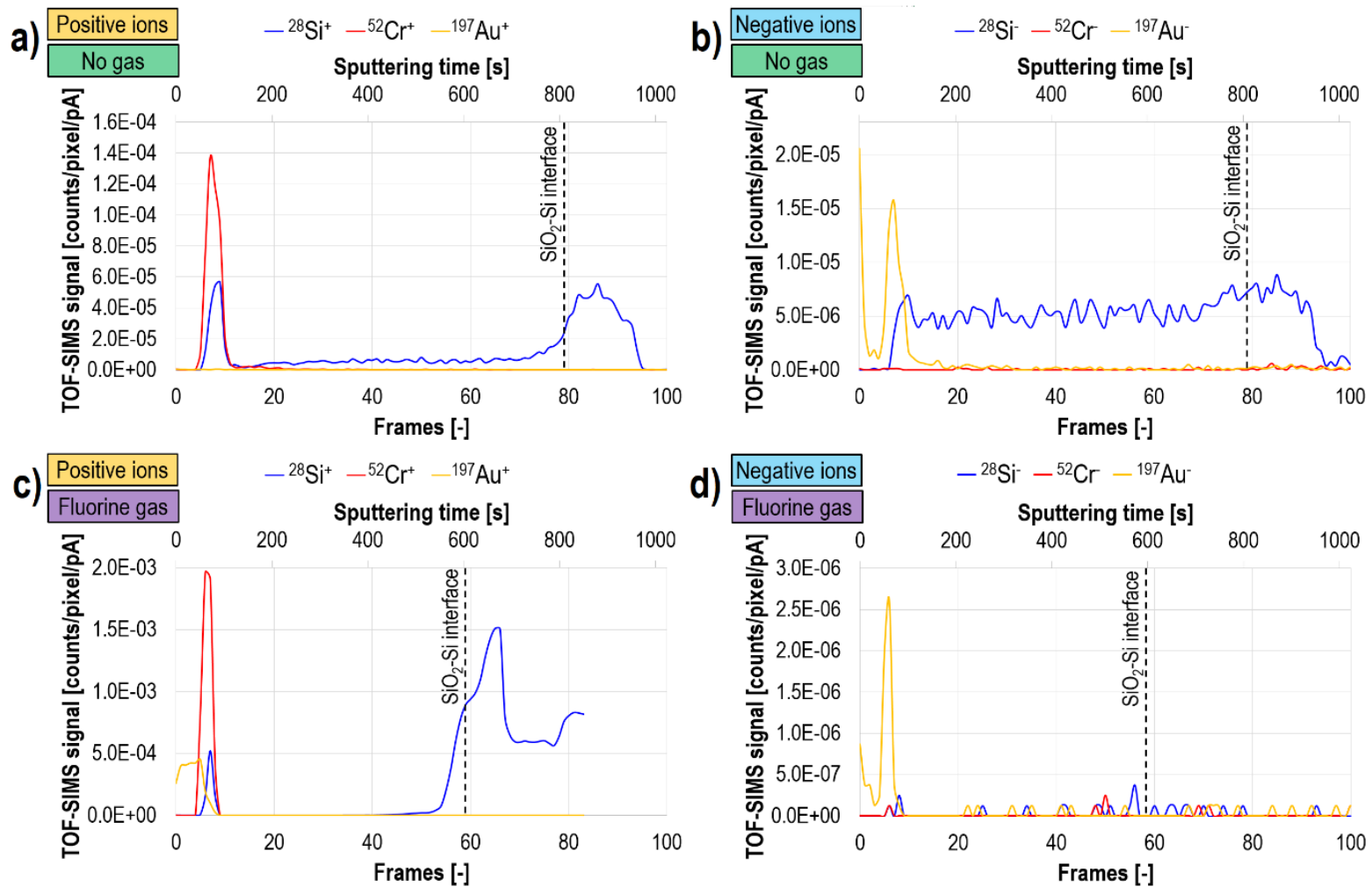

Figure S3. TOF-SIMS depth profiles of $\mathrm{Au} / \mathrm{Cr} / \mathrm{SiO}_{2} / \mathrm{Si}$ sample's main isotopes acquired without (a-b) and with (c-d) fluorine gas. The positive (orange labels) and negative (light blue labels) secondary ion distributions are shown across the sample (i.e. in $z$-direction, signal integration over $x$-y-plane from the central $5 \mu \mathrm{m} \times 5 \mu \mathrm{m} \mathrm{ROI})$. The dashed lines denote the locations $\mathrm{SiO}_{2}-\mathrm{Si}$ interfaces, $t_{S i O 2-S i}$ (i.e. $79 \pm 1$ frames and $58 \pm 1$ frames in the case of measurements conducted without and with fluorine gas, respectively), which were estimated based on the position of $50 \%$ maximum value of the $2^{\text {nd }}$ ascending Si slope. The difference between $t_{S i O 2-S i}$ values results from different sputtering rates. 

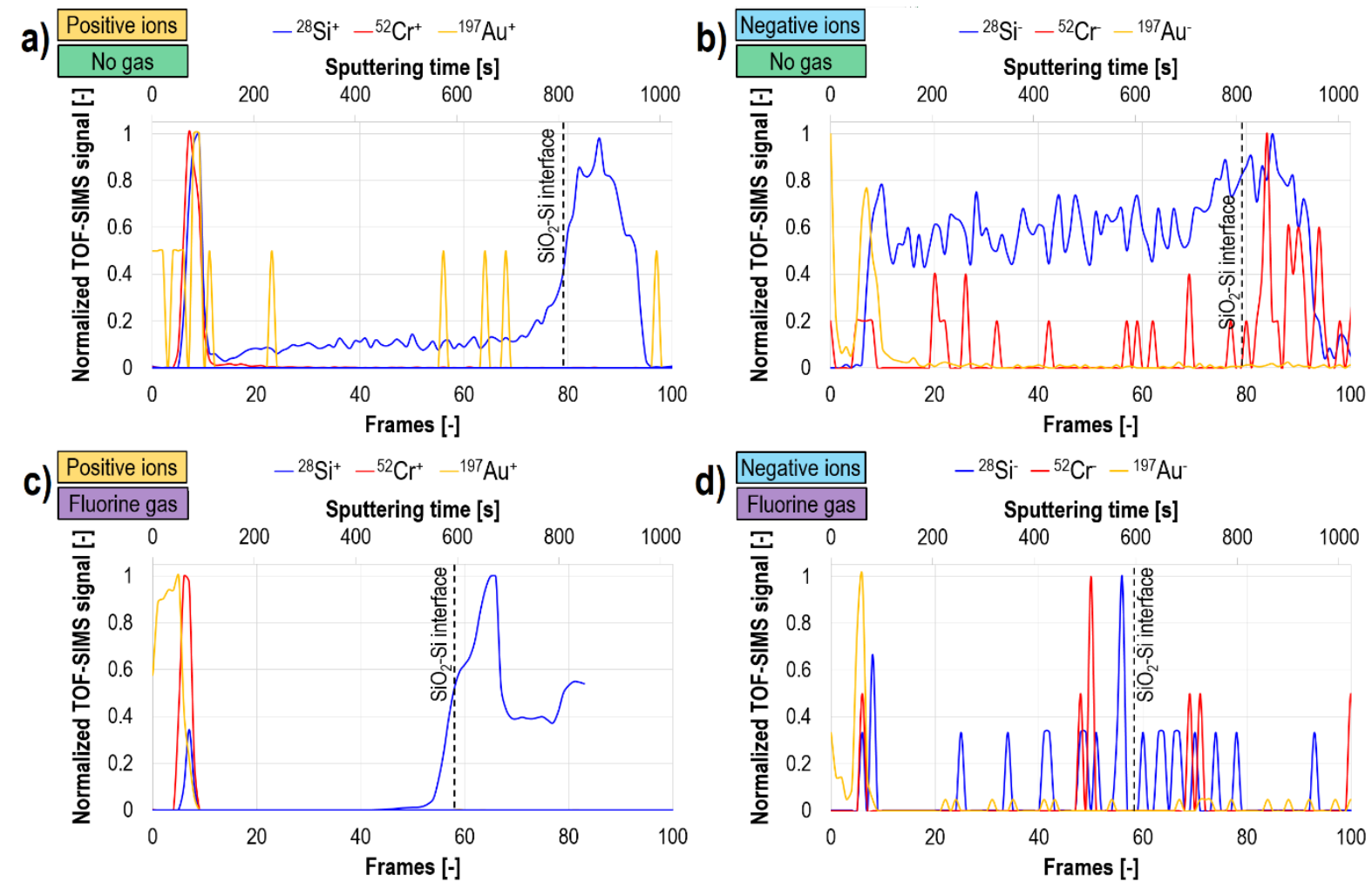

Figure S4. TOF-SIMS depth profiles of $\mathrm{Au} / \mathrm{Cr} / \mathrm{SiO}_{2} / \mathrm{Si}$ sample's main isotopes (Figure $\mathrm{S} 1$ ) normalized to 1 .

Table S2. Summary of the results obtained for the $\mathrm{Au} / \mathrm{Cr} / \mathrm{SiO}_{2} / \mathrm{Si} . S_{\max }$ denotes the maximum signal value in $\left[(\mathrm{m} / \mathrm{Q})_{M^{-}} 0.5,(\mathrm{~m} / \mathrm{Q})_{M+0.5]}\right.$ range for a given isotope, $M$, (shown in Figure 2) and $S_{\text {int }}$ represents a signal integral over this range. Indexes ref and $F$, refer to the data measured without and with fluorine gas. The measured signals were divided by the current (e.g. by 122) to take into account the small variations in primary ion beam currents between the subsequent measurements (i.e. 122-124 pA). The errors were calculated using the signal differences resulting from the uncertainties of estimating the locations of $\mathrm{SiO}_{2}-\mathrm{Si}$ interface, $t_{\mathrm{SiO}-\mathrm{Si}}$, i.e. $\Delta t_{\mathrm{SiO} 2}$ $S i= \pm 1$ frame.

\begin{tabular}{|c|c|c|c|c|}
\hline \multirow{2}{*}{$M$} & $S_{\text {ref,max }}$ & $S_{\text {ref,int }}$ & $S_{F, \max }$ & $S_{F, \text { int }}$ \\
\cline { 2 - 5 } & \multicolumn{4}{|c|}{$[$ counts/pixel/pA] } \\
\hline${ }^{197} \mathrm{Au}^{+}$ & $(1.56 \pm 0.02) \times 10^{-9}$ & $(2.34 \pm 0.03) \times 10^{-8}$ & $(9.9 \pm 0.2) \times 10^{-7}$ & $(4.66 \pm 0.09) \times 10^{-5}$ \\
\hline${ }^{197} \mathrm{Au}^{-}$ & $(2.18 \pm 0.03) \times 10^{-8}$ & $(1.18 \pm 0.02) \times 10^{-6}$ & $(8.6 \pm 0.2) \times 10^{-9}$ & $(1.37 \pm 0.03) \times 10^{-7}$ \\
\hline${ }^{52} \mathrm{Cr}^{+}$ & $(2.17 \pm 0.06) \times 10^{-7}$ & $(6.2 \pm 0.2) \times 10^{-6}$ & $(3.3 \pm 0.2) \times 10^{-6}$ & $(8.9 \pm 0.4) \times 10^{-5}$ \\
\hline${ }^{52} \mathrm{Cr}^{-}$ & $(1.56 \pm 0.04) \times 10^{-9}$ & $(2.80 \pm 0.08) \times 10^{-8}$ & $(2.14 \pm 0.08) \times 10^{-9}$ & $(8.6 \pm 0.3) \times 10^{-9}$ \\
\hline${ }^{28} \mathrm{Si}^{+}$ & $(1.85 \pm 0.04) \times 10^{-7}$ & $(7.5 \pm 0.4) \times 10^{-6}$ & $(2 \pm 1) \times 10^{-6}$ & $(4 \pm 2) \times 10^{-5}$ \\
\hline${ }^{28} \mathrm{Si}^{-}$ & $(1.18 \pm 0.05) \times 10^{-7}$ & $(4.83 \pm 0.06) \times 10^{-6}$ & $(2.14 \pm 0.08) \times 10^{-9}$ & $(3.0 \pm 0.1) \times 10^{-8}$ \\
\hline
\end{tabular}



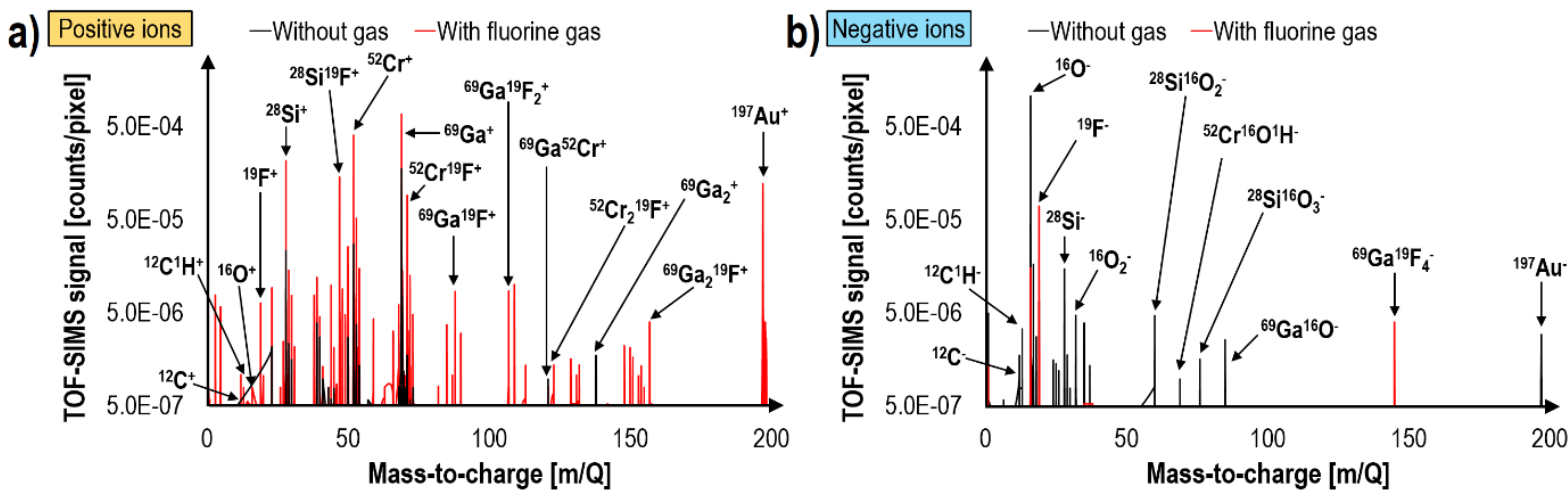

Figure S5. TOF-SIMS mass spectra of $\mathrm{Au} / \mathrm{Cr} / \mathrm{SiO}_{2} / \mathrm{Si}$ acquired in positive (a) and negatvie (b) ion detection modes. The signals were acquired from the same volumes, i.e. $5 \mu \mathrm{m} \times 5 \mu \mathrm{m} \times t_{\text {SiO2-Si, }}$, where $t_{\mathrm{SiO}-\mathrm{Si}}$ was 79 frames and 58 frames, in the case of experiments collected without (black lines) and with fluorine gas (red lines).
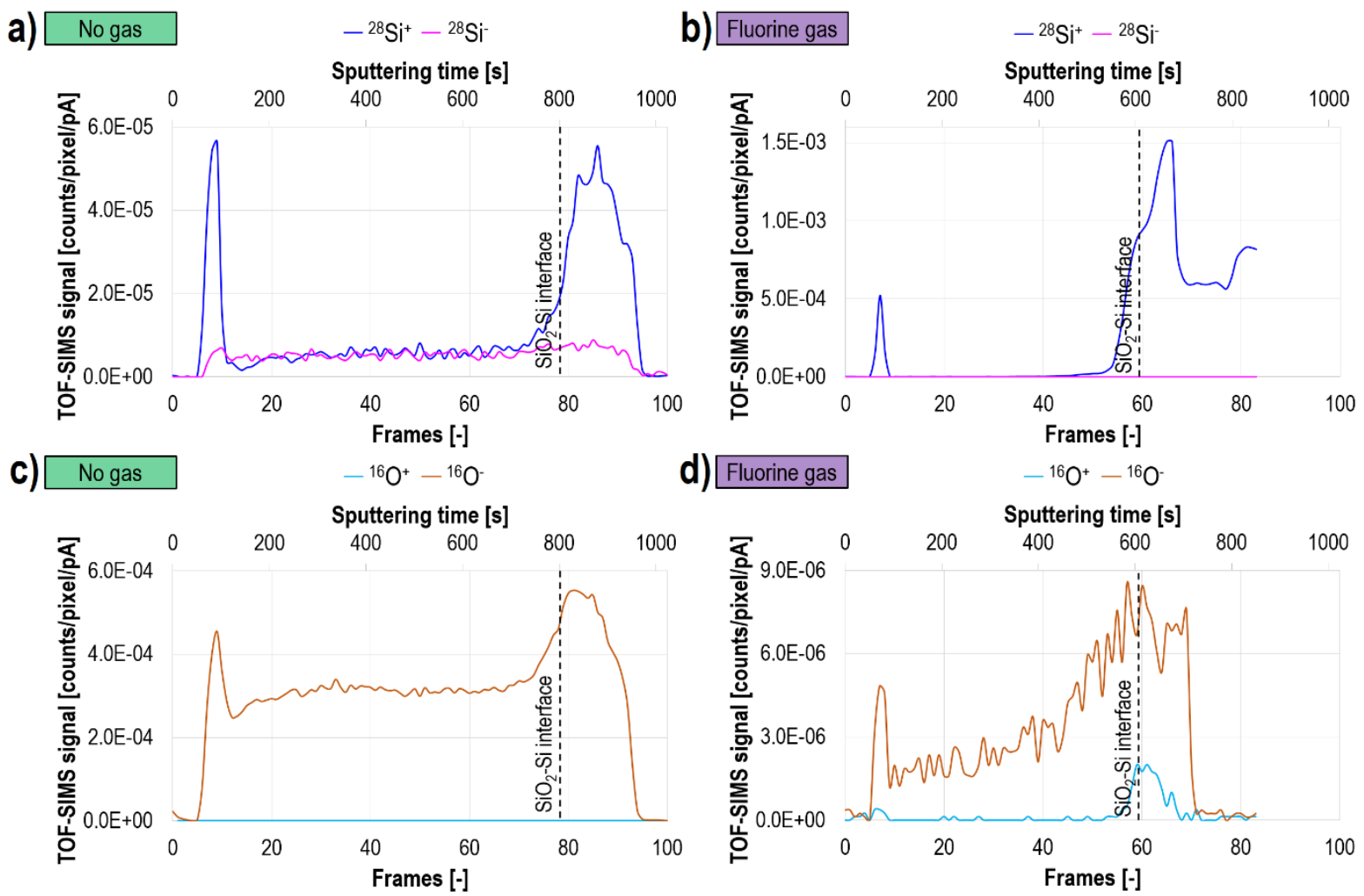

d) Fluorine gas

$-{ }^{16} \mathrm{O}^{+}-{ }^{16} \mathrm{O}$

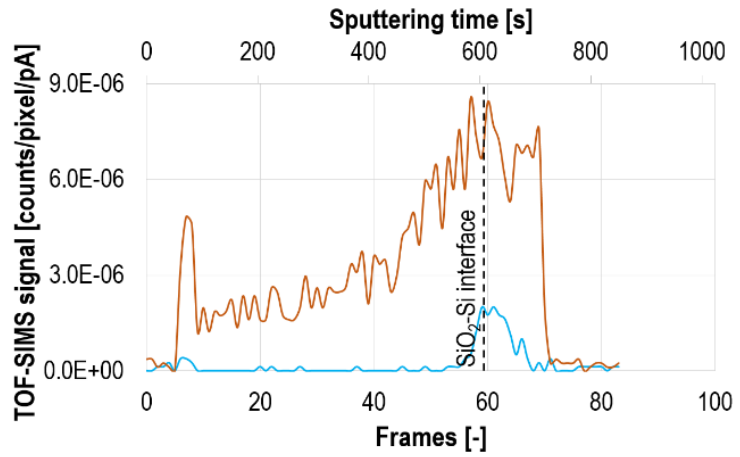

Figure S6. TOF-SIMS depth profiles of ${ }^{28} \mathrm{Si}$ ( $\mathrm{a}$ and $\mathrm{b}$ ) and ${ }^{16} \mathrm{O}$ ( $\mathrm{c}$ and $\mathrm{d}$ ) ion signals in $\mathrm{Au} / \mathrm{Cr} / \mathrm{SiO}_{2} / \mathrm{Si}$. Data measured without (a and c) and with (b and d) fluorine gas. Note different scales. 


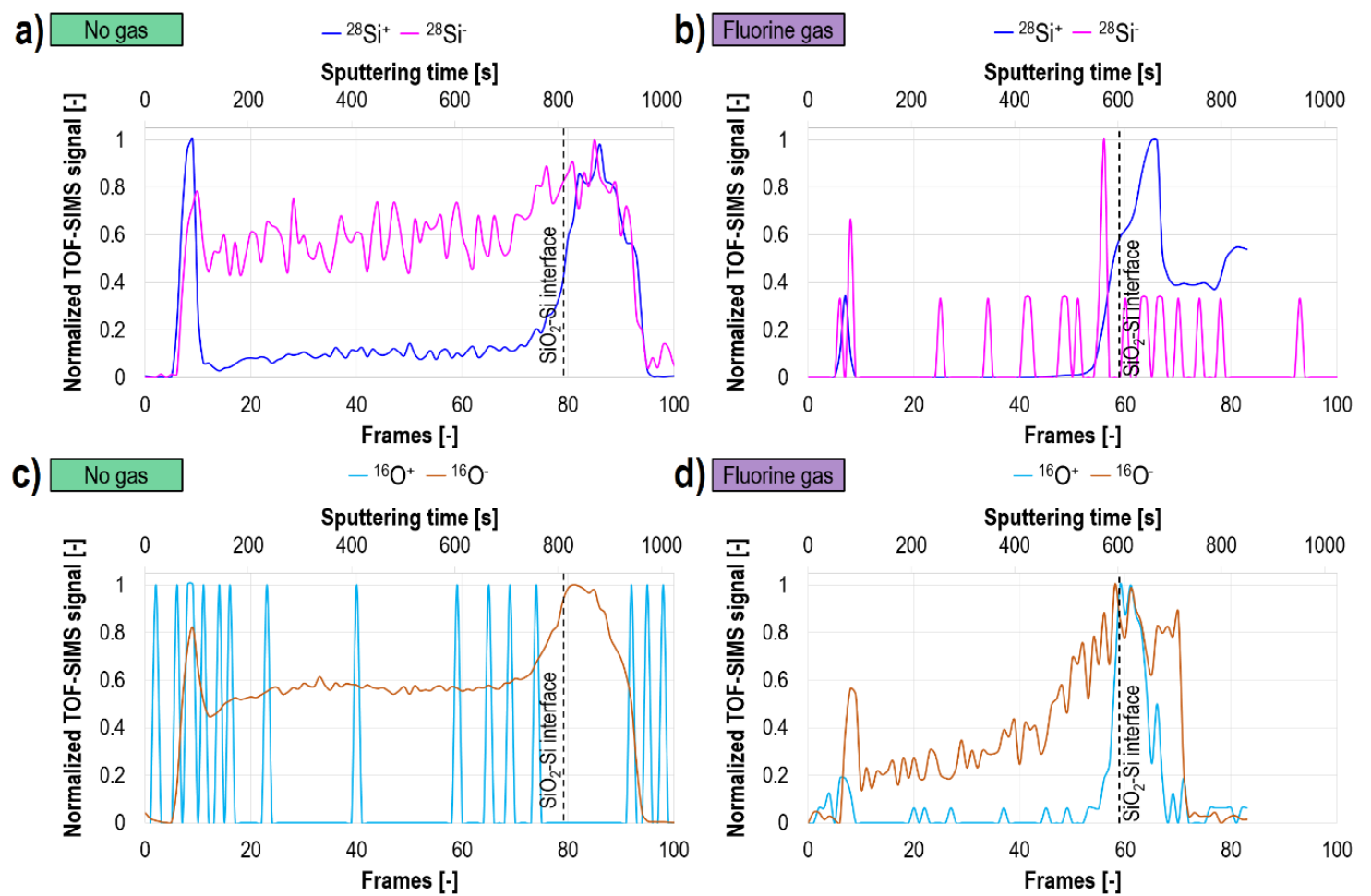

Figure S7. TOF-SIMS depth profiles of ${ }^{28} \mathrm{Si}$ (a and b) and ${ }^{16} \mathrm{O}$ (c and d) ion signals in $\mathrm{Au} / \mathrm{Cr} / \mathrm{SiO}_{2} / \mathrm{Si}$ normalized to 1 . Data measured without (a and c) and with (b and d) fluorine gas.

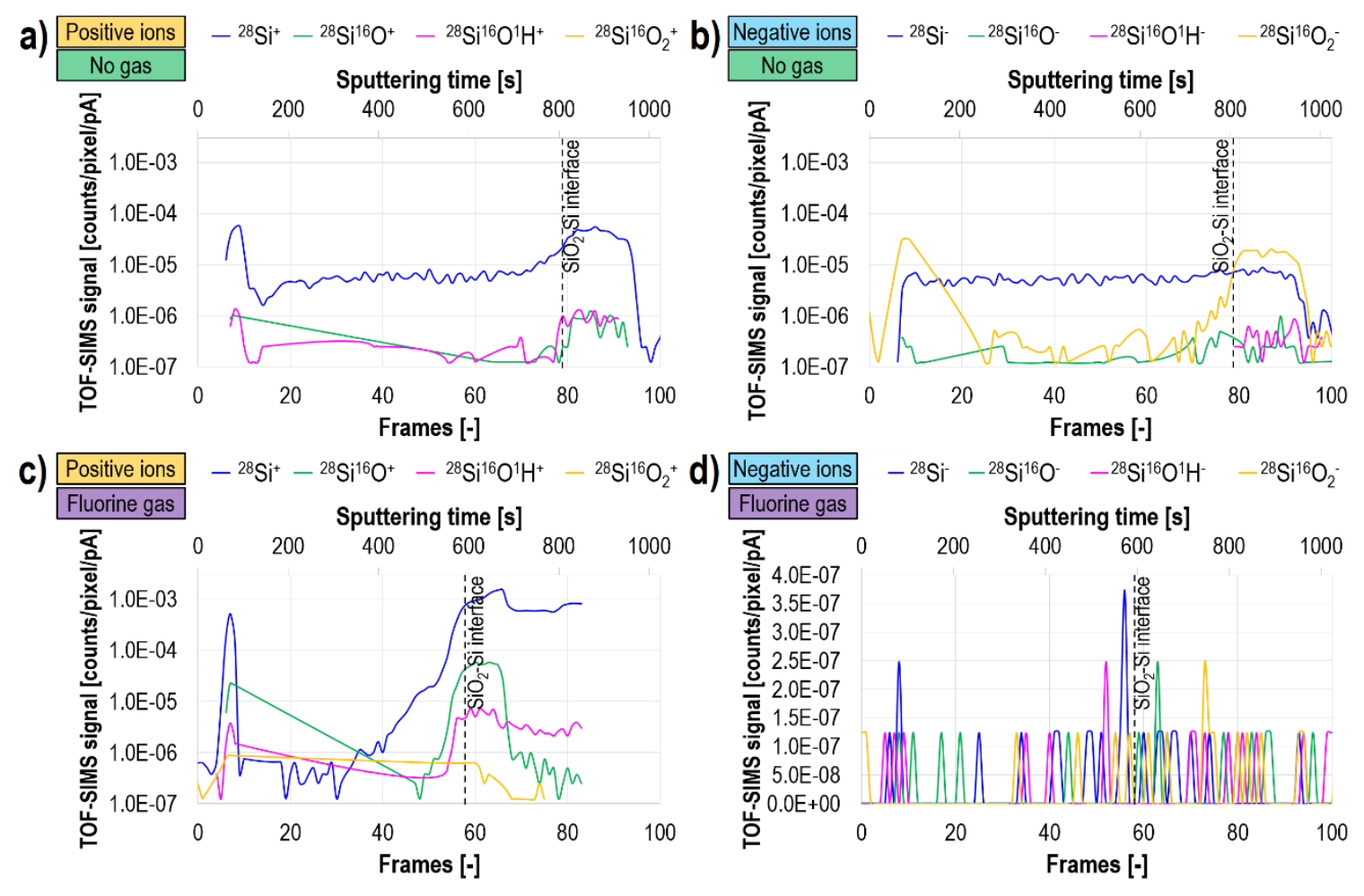

Figure S8. TOF-SIMS depth profiles of Si-containing ions signals measured in $\mathrm{Au} / \mathrm{Cr} / \mathrm{SiO} / \mathrm{Si}$. Data acquired without ( $a$ and $b$ ) and with ( $c$ and d) fluorine gas. Note that figures a-c are given in the logharitmic scale and $b$ is presented in the linear scale. 
a)

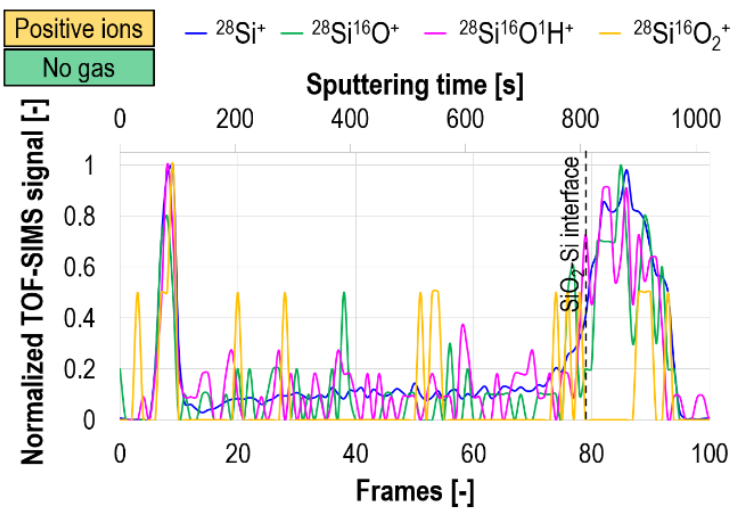

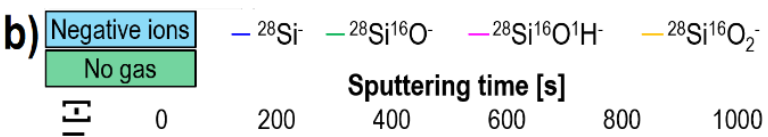

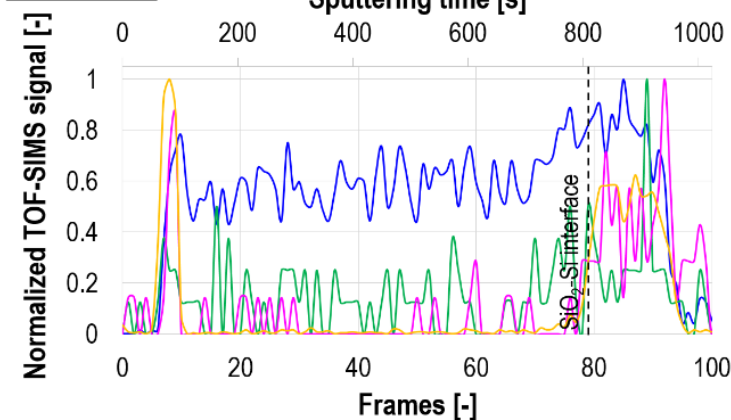

C) Positive ions $-{ }^{28} \mathrm{Si}^{+}-{ }^{28} \mathrm{Si}^{16} \mathrm{O}^{+}-{ }^{28} \mathrm{Si}^{16} \mathrm{O}^{1} \mathrm{H}^{+}-{ }^{28} \mathrm{Si}^{16} \mathrm{O}_{2}{ }^{+}$d)
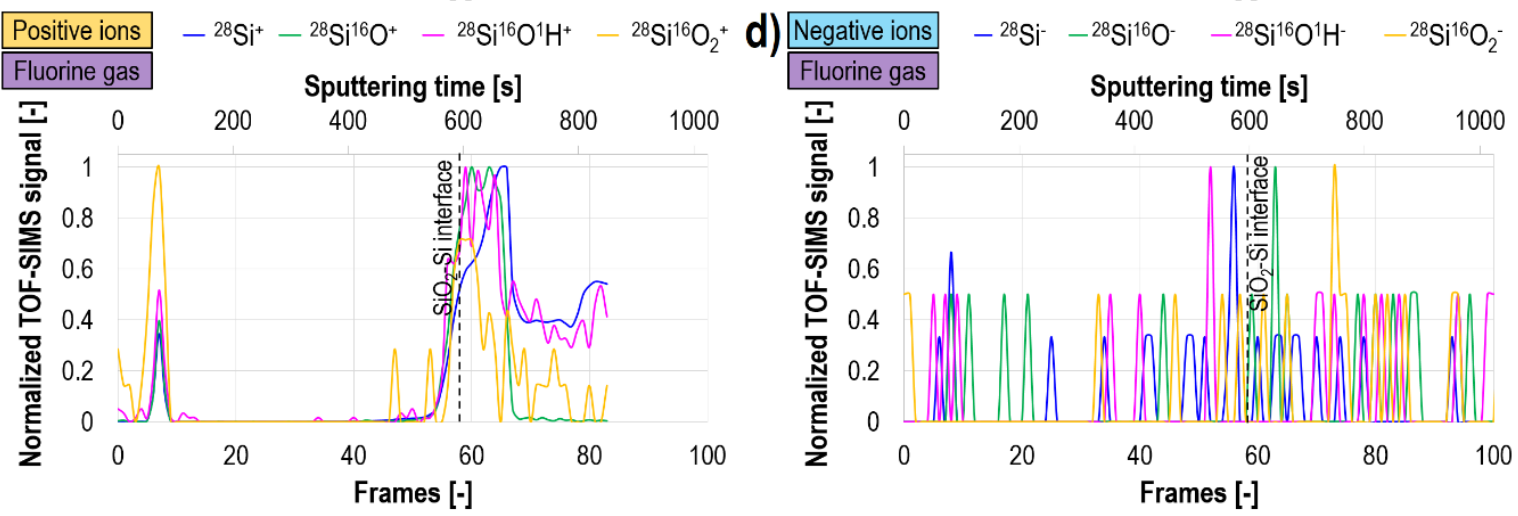

Figure S9. TOF-SIMS depth profiles of Si-containing ions signals measured in $\mathrm{Au} / \mathrm{Cr} / \mathrm{SiO}_{2} / \mathrm{Si}$ normalized to 1. Data obtained without ( $a$ and b) and with ( $c$ and d) fluorine gas.
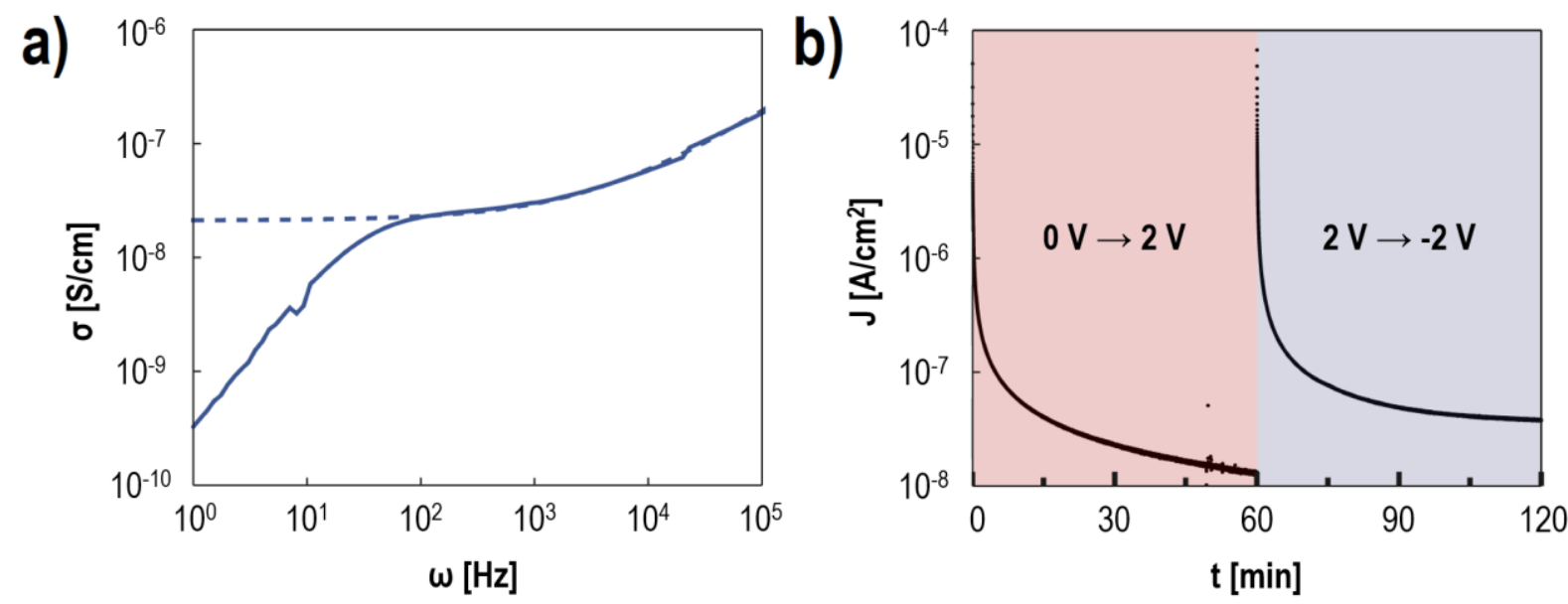

Figure S10. Electrochemical measurements of $\mathrm{Au} / \mathrm{Li}_{7} \mathrm{La}_{3} \mathrm{Zr}_{2} \mathrm{O}_{12} / \mathrm{Pt} / \mathrm{MgO} / \mathrm{Si}$. a) The conductivity of the sample (the solid line) was measured using impedance spectroscopy. The fit (the dashed line) allows the ionic conductivity of the film to be evaluated $\left.\left(2 \times 10^{-8} \mathrm{~S} / \mathrm{cm}^{2}\right) . \mathrm{b}\right)$ Polarization measurements were conducted by applying subsequently positive and negative voltage bias. The current measured in the steady state (i.e. after 60 minutes) represents the electronic conductivity of the film $\left(3 \times 10^{-14} \mathrm{~S} / \mathrm{cm}^{2}\right)$. 
a) No gas $-{ }^{7} \mathrm{Li}^{+}-{ }^{24} \mathrm{Mg}^{+}-{ }^{90} \mathrm{Zr}^{+}-{ }^{139} \mathrm{La}^{+}-{ }^{195} \mathrm{Pt}^{+}-{ }^{197} \mathrm{Au}^{+}$b)

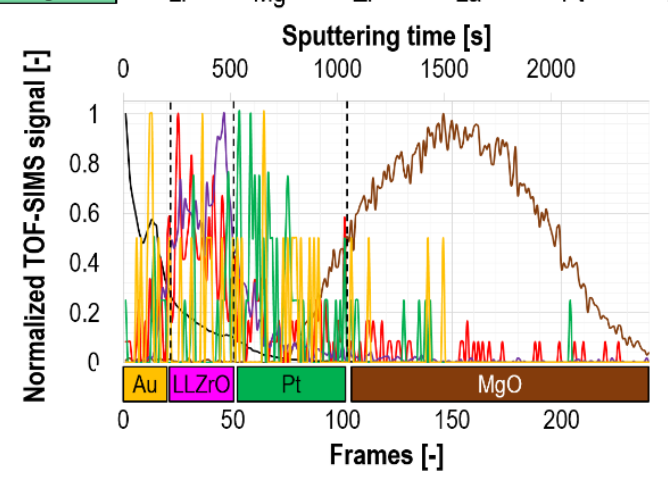

b) Fluorine gas $-{ }^{7} \mathrm{Li}^{+}-{ }^{24} \mathrm{Mg}^{+}-{ }^{90} \mathrm{Zr}^{+}-{ }^{139} \mathrm{La}^{+}-{ }^{195} \mathrm{Pt}^{+} \quad{ }^{197} \mathrm{Au}^{+}$ Sputtering time [s]

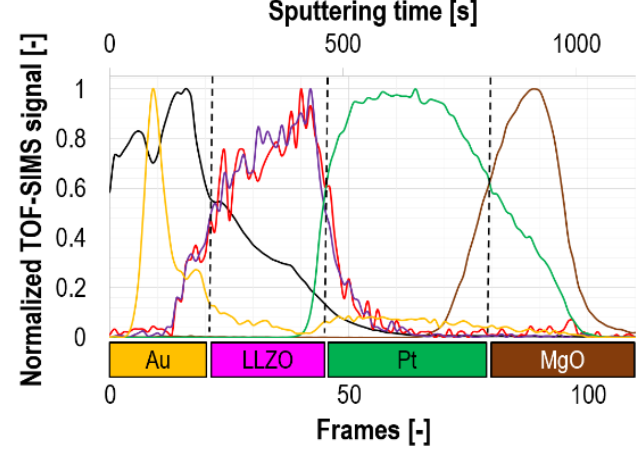

Figure S11. TOF-SIMS depth profiles of $\mathrm{Au} / \mathrm{Li}_{7} \mathrm{La}_{3} \mathrm{Zr}_{2} \mathrm{O}_{12} / \mathrm{Pt} / \mathrm{MgO} / \mathrm{Si}$ normalized to 1 . The sample was measured under standard vacuum conditions (a) and in the presence of fluorine gas (b). The dashed black lines indicate the locations of interfaces between the layers, which were estimated based on the locations of cross-point between the ascending and descending signal distributions of two neighbouring layers or at the $50 \%$ of ascending/descending signal distribution.

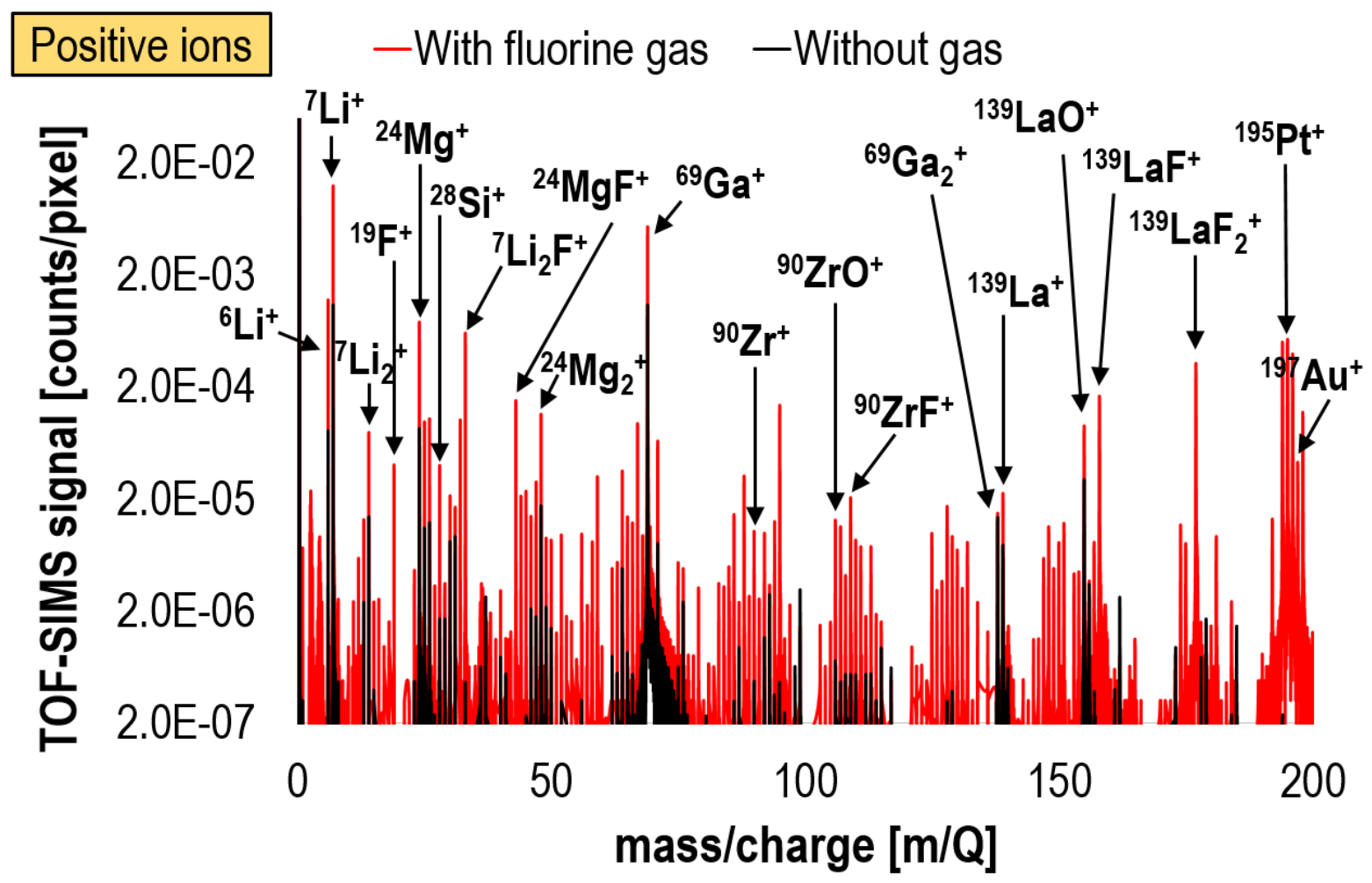

Figure S12. TOF-SIMS mass spectra of $\mathrm{Au} / \mathrm{Li}_{7} \mathrm{La}_{3} \mathrm{Zr}_{2} \mathrm{O}_{12} / \mathrm{Pt} / \mathrm{MgO} / \mathrm{Si}$. The signals were acquired from the same volumes, i.e. $5 \mu \mathrm{m} \times 5 \mu \mathrm{m} \times t_{M g O-S i}$, where $t_{\mathrm{MgO}-S i}$ is the time of reaching the $\mathrm{MgO}-\mathrm{Si}$ interface (estimated based on $50 \%$ of the descending ${ }^{24} \mathrm{Mg}^{+}$slope given in Figure S11) equals to 196 frames and 95 frames, in the case of experiments collected without (black lines) and with fluorine gas (red lines). 

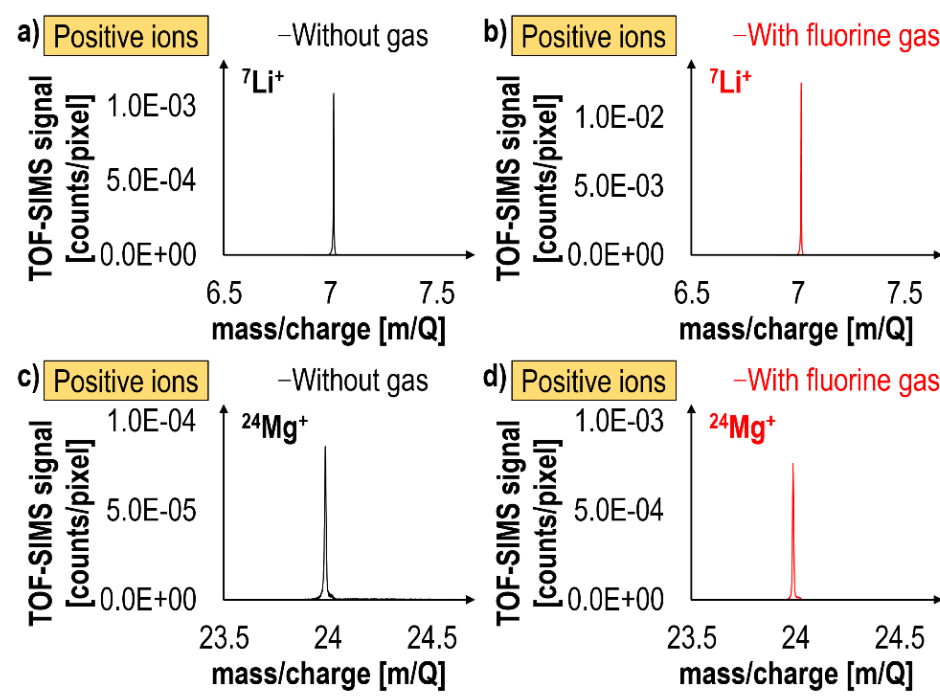

d) Positive ions -With fluorine gas
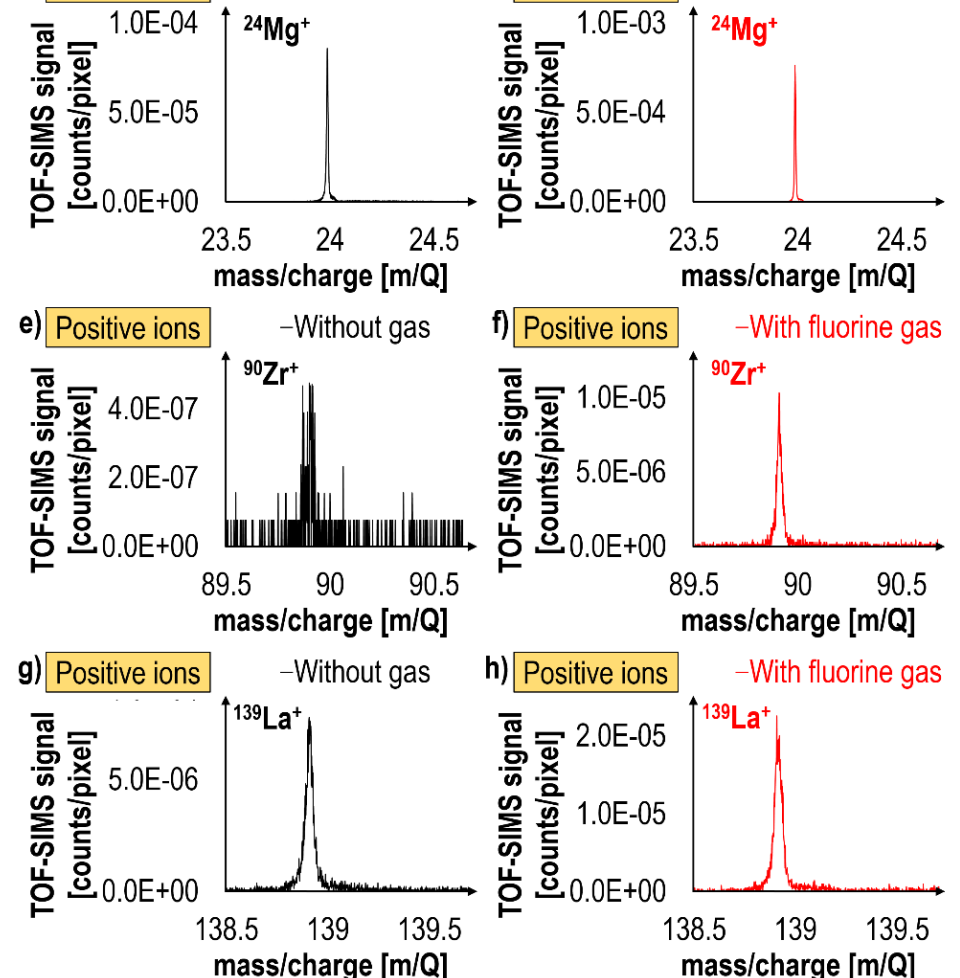

h) Positive ions -With fluorine gas
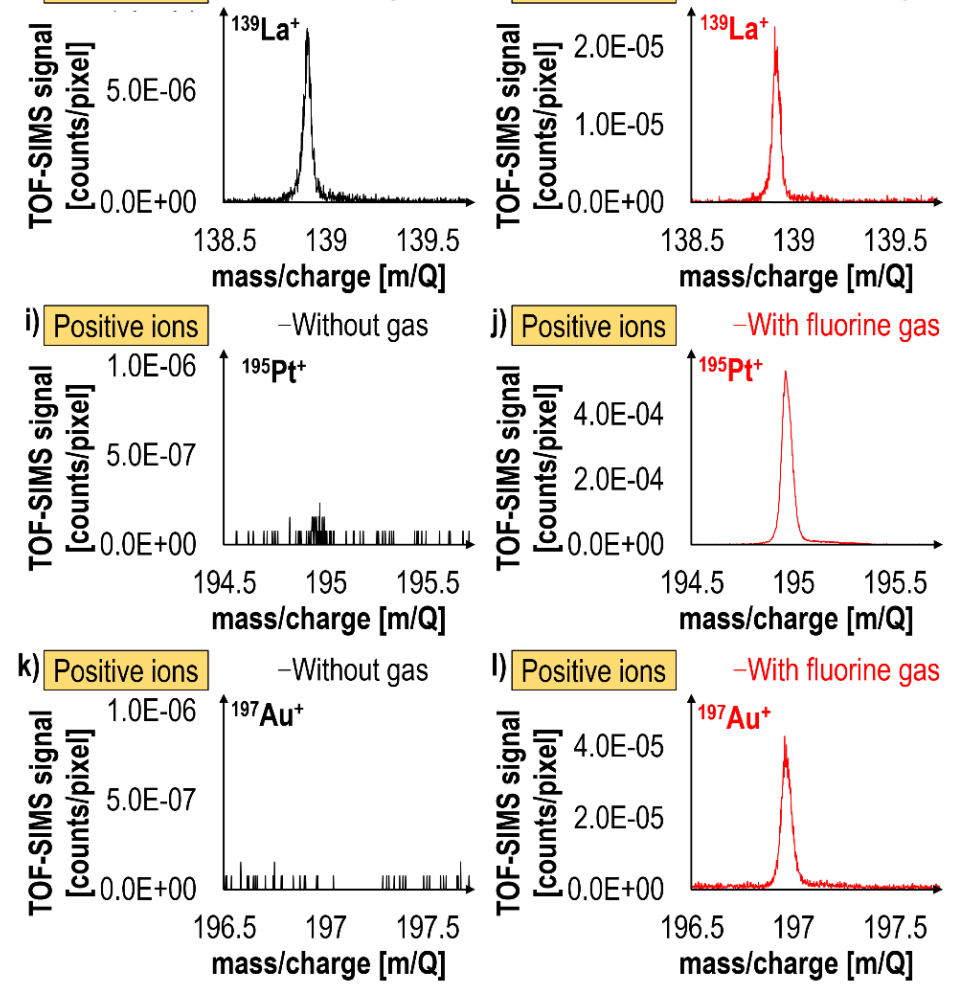

Figure $\mathrm{S} 13$. The TOF-SIMS mass spectrum ranges of $\mathrm{Au} / \mathrm{Li}_{7} \mathrm{La}_{3} \mathrm{Zr}_{2} \mathrm{O}_{12} / \mathrm{Pt} / \mathrm{MgO} / \mathrm{Si}$ corresponding to ${ }^{7} \mathrm{Li}^{+}$(a and b), ${ }^{24} \mathrm{Mg}^{+}$(c and d), ${ }^{90} \mathrm{Zr}^{+}$(e and f), ${ }^{139} \mathrm{La}^{+}$(g and h), ${ }^{195} \mathrm{Pt}^{+}$(i and j), ${ }^{197} \mathrm{Au}^{+}(\mathrm{k}$ and l) ion acquired under standard vacuum conditions (a, c, e, g, i and k) and with the presence of fluorine gas (b, d, f, h, j and l). The entire TOF-SIMS mass spectrum is shown in Figure S12. 
Table S3: Summary of the TOF-SIMS results obtained for the main isotopes of $\mathrm{Au} / \mathrm{Li}_{7} \mathrm{La}_{3} \mathrm{Zr}_{2} \mathrm{O}_{12} / \mathrm{Pt} / \mathrm{MgO} / \mathrm{Si}$. $S_{\max }$ denotes the maximum signal peak in the range of

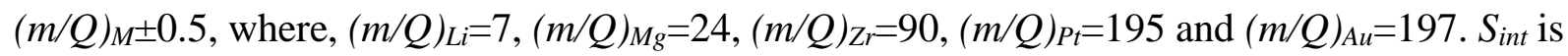
a signal integral over $\left[(\mathrm{m} / Q)_{M}-0.5,(\mathrm{~m} / Q)_{M}+0.5\right]$ range. Indexes $r e f$ and $F$ refer to the data acquired without and with fluorine gas, respectively. The errors were calculated using the signal differences resulting from the uncertainties of estimating the locations of $\mathrm{MgO}-\mathrm{Si}$ interface, i.e. $\Delta t_{M g O-S i, r e f}= \pm 1$ frame and $\Delta t_{M g O-S i, F}= \pm 2$.

\begin{tabular}{|c|c|c|c|c|}
\hline \multirow{2}{*}{$M$} & $S_{\text {ref,max }}$ & $S_{\text {ref,int }}$ & $S_{F, \max }$ & $S_{F, \text { inf }}$ \\
\cline { 2 - 5 } & \multicolumn{4}{|c|}{$[$ counts/pixel/pA] } \\
\hline${ }^{7} \mathrm{Li}^{+}$ & $(1.04 \pm 0.02) \times 10^{-5}$ & $(1.57 \pm 0.02) \times 10^{-4}$ & $(1.13 \pm 0.02) \times 10^{-4}$ & $(1.40 \pm 0.02) \times 10^{-3}$ \\
\hline${ }^{24} \mathrm{Mg}^{+}$ & $(8.26 \pm 0.04) \times 10^{-7}$ & $(2.115 \pm 0.006) \times 10^{-5}$ & $(6.9 \pm 0.3) \times 10^{-6}$ & $(1.15 \pm 0.04) \times 10^{-4}$ \\
\hline${ }^{90} \mathrm{Zr}^{+}$ & $(4.49 \pm 0.05) \times 10^{-9}$ & $(2.43 \pm 0.03) \times 10^{-7}$ & $(9.3 \pm 0.1) \times 10^{-8}$ & $(3.01 \pm 0.03) \times 10^{-6}$ \\
\hline${ }^{139} \mathrm{La}^{+}$ & $(7.49 \pm 0.08) \times 10^{-8}$ & $(3.35 \pm 0.04) \times 10^{-6}$ & $(2.03 \pm 0.03) \times 10^{-7}$ & $(8.12 \pm 0.09) \times 10^{-6}$ \\
\hline${ }^{195} \mathrm{Pt}^{+}$ & $(2.25 \pm 0.03) \times 10^{-9}$ & $(6.21 \pm 0.07) \times 10^{-8}$ & $(4.83 \pm 0.04) \times 10^{-6}$ & $(2.11 \pm 0.02) \times 10^{-4}$ \\
\hline${ }^{197} \mathrm{Au}^{+}$ & $(1.50 \pm 0.02) \times 10^{-9}$ & $(2.62 \pm 0.03) \times 10^{-8}$ & $(3.86 \pm 0.05) \times 10^{-7}$ & $(1.91 \pm 0.02) \times 10^{-5}$ \\
\hline
\end{tabular}

Table S4. Summary of gas enhancement factors for TOF-SIMS signals obtained for the $\mathrm{Au} / \mathrm{Li}_{7} \mathrm{La}_{3} \mathrm{Zr}_{2} \mathrm{O}_{12} / \mathrm{Pt} / \mathrm{MgO} / \mathrm{Si}$ main isotopes (calculations were done using the data given in Table S3). Indexes max and int denote the values calculated using signal maxima and signal integrals, respectively. The errors were calculated using an exact differential.

\begin{tabular}{|c|c|c|}
\hline \multirow{2}{*}{$M$} & GAE $E_{\text {TOF-SIMS,max }}$ & GAE TOF-SIMS,int $^{|c|}$ \\
\cline { 2 - 3 } & \multicolumn{2}{|c|}{} \\
\hline${ }^{7} \mathrm{Li}^{+}$ & $10.9 \pm 0.5$ & $8.9 \pm 0.3$ \\
\hline${ }^{24} \mathrm{Mg}^{+}$ & $8.4 \pm 0.5$ & $5.4 \pm 0.2$ \\
\hline${ }^{90} \mathrm{Zr}^{+}$ & $20.7 \pm 0.5$ & $12.4 \pm 0.3$ \\
\hline${ }^{139} \mathrm{La}^{+}$ & $2.71 \pm 0.07$ & $2.42 \pm 0.06$ \\
\hline${ }^{195} \mathrm{Pt}^{+}$ & $2150 \pm 50$ & $3400 \pm 80$ \\
\hline${ }^{197} \mathrm{Au}^{+}$ & $257 \pm 7$ & $730 \pm 20$ \\
\hline
\end{tabular}




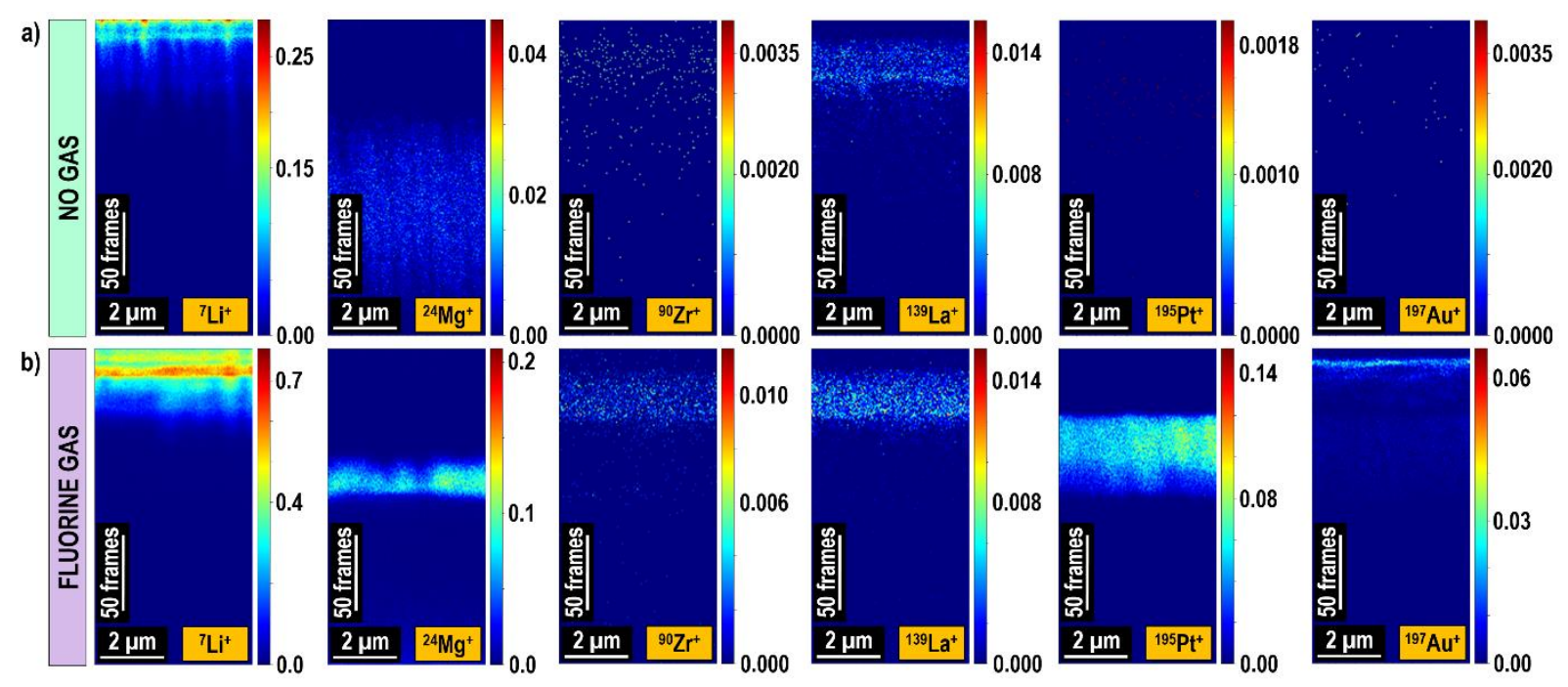

Figure S14. 2D elemental maps of $\mathrm{Au} / \mathrm{Li}_{7} \mathrm{La}_{3} \mathrm{Zr}_{2} \mathrm{O}_{12} / \mathrm{Pt} / \mathrm{MgO} / \mathrm{Si}$ main isotopes obtained during TOF-SIMS measurements conducted under standard vacuum conditions (a) and in the presence of fluorine gas (b). 